Article

\title{
Epitope Mapping Immunoassay Analysis of the Interaction between $\beta$-Amyloid and Fibrinogen
}

\author{
Vo Van Giau $(\mathbb{1}$ and Seong Soo A. An *(1) \\ Department of Bionano Technology, Gachon University, Seongnam, 1342 Sungnamdaero, Sujeong-Gu, \\ Seongnam, Gyeonggi 461-701, Korea; giauvvo@gmail.com or giauvvo@gachon.ac.kr \\ * Correspondence: seongaan@gachon.ac.kr or seong.an@gmail.com; Tel./Fax: +82-31-750-8755
}

Received: 27 December 2018; Accepted: 21 January 2019; Published: 24 January 2019

\begin{abstract}
The vast majority of patients with Alzheimer's disease (AD) suffer from impaired cerebral circulation. Substantial evidence indicates that fibrinogen (Fbg) and fibrin clot formation play an important role in this circulatory dysfunction in AD. Fbg interacts with $\beta$-amyloid (1-42) $(A \beta)$, forming plasmin-resistant abnormal blood clots, and increased fibrin deposition has been discovered in the brains of $\mathrm{AD}$ patients and mouse models. In this study, biochemical approaches and the epitope mapping immunoassay were employed to characterize binding epitopes within the Fbg and complementary epitopes in $A \beta$. We discovered the $A \beta 5-25$ peptide as the most critical region for the interaction, which can be inhibited by specific monoclonal and polyclonal antibodies against the central region of $A \beta$. A $\beta$ binding to Fbg may block plasmin-mediated fibrin cleavage at this site, resulting in the generation of increased levels of plasmin-resistant fibrin degradation fragments. Our study elucidates the $\mathrm{A} \beta-\mathrm{Fbg}$ interaction that may involve the mechanism by which $\mathrm{A} \beta-\mathrm{Fbg}$ binding delays fibrinolysis by plasmin, providing valuable information in the development of therapeutic approaches for AD.
\end{abstract}

Keywords: Alzheimer's disease; amyloid- $\beta$; epitope mapping; ligand; fibrinogen

\section{Introduction}

Alzheimer's disease (AD) is a neurodegenerative disease in which vascular pathology plays a vital role [1-4]. The most important and well-known pathological features of AD are extracellular $\beta$-amyloid (1-42) (A $\beta$ ) plaques, intracellular tau tangles, neuroinflammation, and neuronal loss [5]. Fibrinogen (Fbg) is a large glycoprotein, composed of two fragment D domains and one fragment $\mathrm{E}$ domain, which consist of a heterodimer composed of pairs of $\alpha, \beta$, and $\gamma$ chains [6]. There are several functional consequences of binding of $\mathrm{A} \beta$ to $\mathrm{Fbg}$, which induces a structural change in the $\mathrm{C}$-terminal region of the $\mathrm{Fbg} \beta$-chain ( $\beta 384-393$ ) [7] and results in the formation of fibrin with increased resistance to fibrinolysis $[7,8]$. Accumulating evidence implicates Fbg, the main protein component of blood clots, in the pathogenesis of AD. Hence, disturbances to fibrinolysis may have significant consequences for occlusive and inflammatory pathology in various diseases [3] including AD [9]. Indeed, many studies suggested that the interaction between Fbg and $A \beta$ resulted in forming plasmin-resistant abnormal blood clots, which may be increased fibrin deposition in the brains of AD patients and mouse models [8,10-12]. Fibrin clots can contribute to the pathology of AD by forming occlude capillaries and restricting blood flow. Furthermore, previous studies demonstrated that the $\mathrm{A} \beta$ was a factor capable of modulating fibrin clot structure and stability $[7,13]$. A $\beta 42$ bound Fbg with a Kd of $26.3 \pm 6.7 \mathrm{nM} 7$, as well as fibrin clots formed in the presence of $A \beta 42$, are structurally altered and more resistant to fibrinolysis. A $\beta 42$ can also bind to pre-formed fibrin and block the access of plasmin to fibrin [7]. Over time, this could lead to disruption of microinfarcts and the blood-brain barrier, which 
are pathologies commonly observed in $\mathrm{AD}$. To improve selectivity and potency of therapeutics against the $A \beta-F b g$ interaction, a better understanding of their interaction is needed.

In the present study, we discovered the regions within $A \beta$ responsible for $A \beta-F b g$ binding using biochemical approaches and the epitope-mapping enzyme-linked immunosorbent assay (ELISA).

\section{Results}

\subsection{The Preparation of Fbg and A 42 EpiMap ELISA Tests}

The EpiMap ELISA was prepared from an array of synthetic peptides on 96-well microtiter plates using 14 overlapping peptides ( 15 mer) from the $\mathrm{N}$ - to C-terminus of the $\mathrm{A} \beta 42$ sequence (Figure 5 ). Overlapping peptides were synthesized with a cysteine residue at the $\mathrm{N}$ - or $\mathrm{C}$-terminal ends to conjugate on the maleimide-activated microplates through their free sulfhydryl group. Increased hydrophobicity of overlapping peptides was encouraged with the addition of a cysteine. Unfortunately, the $\mathrm{A} \beta$ peptide no. 15 could not be purified due to its aggregation upon release from the solid-phase peptide synthesis beads. The overlapping peptides were conjugated to a maleimide-activated microplate through a cysteine residue. A schematic explanation of the overlapping peptide conjugation as well as the basic principle of the EpiMap ELISA test is described in Figure 6.

\subsection{The Evaluation of Specificity and Sensitivity of the Antibodies}

The specificity and sensitivity of the antibodies used in this study, polyclonal rabbit anti-Fbg (pAb) and monoclonal anti-Fbg 85D4 (mAb), were checked with the indirect ELISA system. The pAb had an affinity to Fbg including its fragments $\mathrm{D}$ and $\mathrm{E}$, while $\mathrm{mAb}$, capturing only a specific conformational epitope in Fbg fragment D, only had an affinity for Fbg fragment D. Interestingly, Fbg itself showed little binding with $\mathrm{mAb}$ even though it contained the $\mathrm{Fbg}$ fragment $\mathrm{D}$ detected by $\mathrm{mAb}$ (Figure 1 ). Previous results show that the interaction between $A \beta 42$ and Fbg or fragment $D$ promotes $A \beta 42$ fibrillization $[13,14]$, which may account for the conversion of the oligomeric species of $A \beta 42$ seen when incubated alone into fibrils in the presence of fragment D.
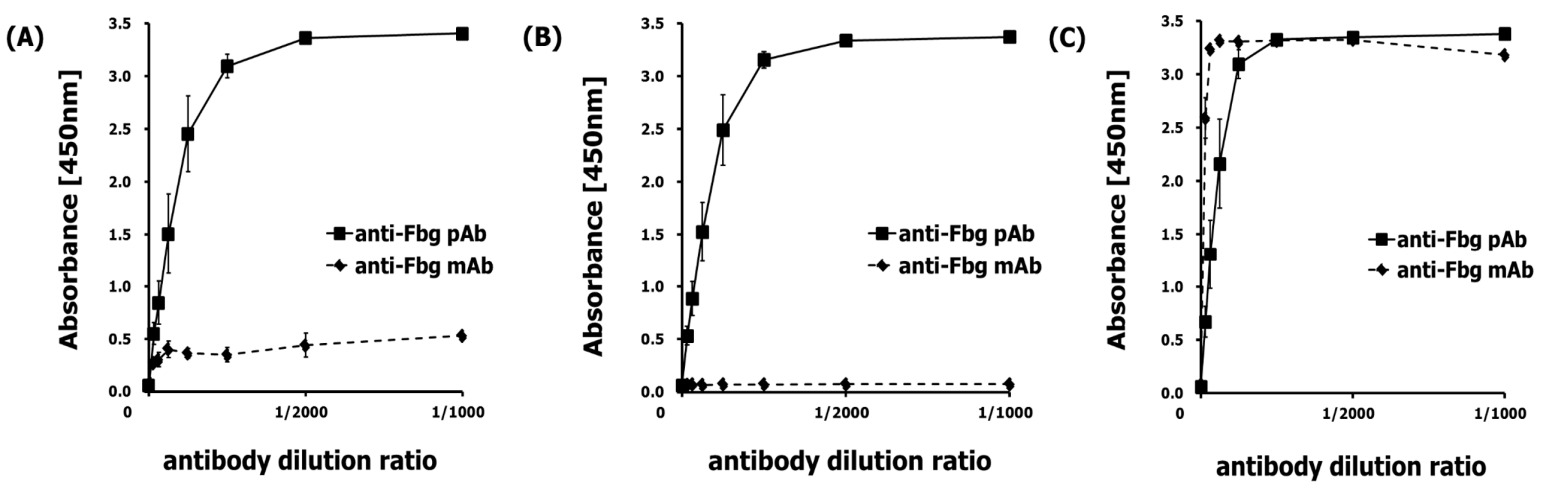

Figure 1. Each anti-Fbg, pAb and $\mathrm{mAb}$, was tested using the indirect ELISA system. (A) At an Fbg-coated plate, the $\mathrm{pAb}$ had good affinity while the mAb had poor affinity. (B) At an Fbg fragment E-coated plate, the pAb had good affinity while the mAb had no affinity. (C) At an Fbg fragment $\mathrm{D}$-coated plate, both the pAb and the mAb had good affinity.

\subsection{Protein Epitope Mapping with the EpiMap ELISA}

Our ELISA-based protein interaction assay was designed to investigate the interaction between Fbg and $A \beta$. Binding of Fbg at $A \beta$-coated plates was detected by both the $\mathrm{pAb}$ and the $\mathrm{mAb}$. Fbg $(340 \mathrm{kDa})$ is composed of 2 sets of 3 polypeptide chains $(\mathrm{A} \alpha: 67 \mathrm{kDa}, \mathrm{B} \beta: 52 \mathrm{kDa}, \gamma: 46.5 \mathrm{kDa})$, its fragment $\mathrm{E}(\sim 50 \mathrm{kDa})$ is composed of truncated small chains $(\mathrm{E} \alpha: 11 \mathrm{kDa}, \mathrm{E} \beta: 14 \mathrm{kDa}, \mathrm{E} \gamma: 7 \mathrm{kDa})$, and its fragment $\mathrm{D}(85 \mathrm{kDa})$ is composed of truncated longer chains $(\mathrm{D} \alpha: 12 \mathrm{kDa}, \mathrm{D} \beta: 37.6 \mathrm{kDa}, \mathrm{D} \gamma$ : $41 \mathrm{kDa}$ ). All three complexes were identified by a published gel electrophoretic method [15] (Figure 2A). 
At $500 \mu \mathrm{g} / \mathrm{mL}$ in $100 \mathrm{mM}$ carbonate-bicarbonate buffer, the $\mathrm{A} \beta$ stock solution was composed of monomers $(4 \mathrm{kDa})$, oligomers $(8-16 \mathrm{kDa}$ ), and fibrils (approximately $>70 \mathrm{kDa}$ ) (Figure $2 \mathrm{~B}$ ). Although a high-concentration solution of $A \beta$ was used for electrophoresis due to the high detection limit of that assay, the $\mathrm{A} \beta$ used to coat ELISA plates had been diluted to $2 \mu \mathrm{g} / \mathrm{mL}$ in the carbonate-bicarbonate buffer, which would have lowered the degree of polymerization. The pAb interacted with Fbg and Fbg fragment $\mathrm{D}$ in proportion to their concentrations, while rarely interacting with Fbg fragment $\mathrm{E}$ even at high concentrations (Figure $2 \mathrm{C}$ ). Similar to the $\mathrm{pAb}$, the mAb interacted with both Fbg and Fbg fragment $\mathrm{D}$ in proportion to their concentrations, while no interaction between the $\mathrm{mAb}$ and $\mathrm{Fbg}$ fragment $E$ could be detected (Figure 2D). These findings are similar to previous studies $[13,14]$ that found $\mathrm{Ab} 42$ binding to fibrin(ogen) delays fibrinolysis by interfering with the binding of plasminogen and plasmin to fibrin [7] and that $\mathrm{Ab} 42$ binds to the $\beta$-chain of Fbg fragment D.

(A)

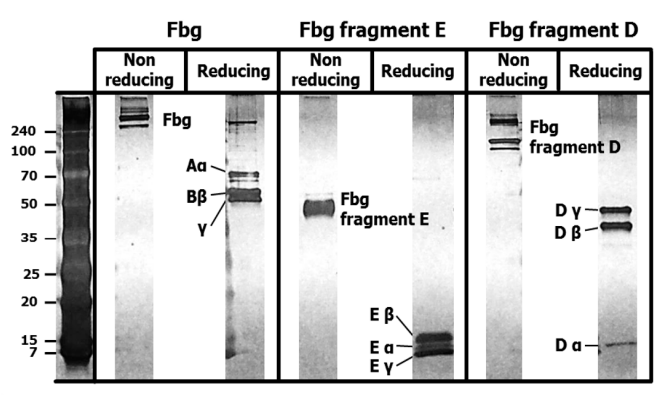

(C)

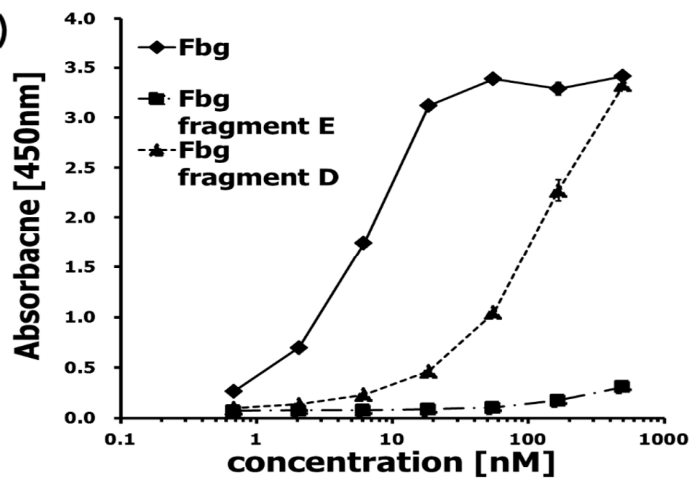

(B)

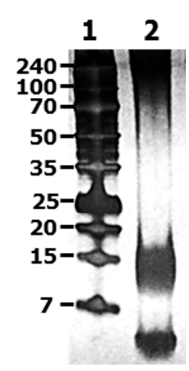

(D)

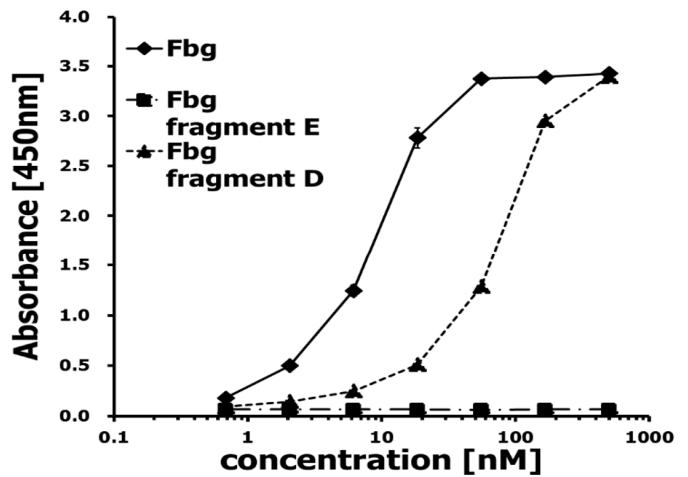

Figure 2. $A \beta 42$ binds to Fbg and its fragments. (A) Tris-tricine gel electrophoresis result for Fbg and its fragments D and E. (B) Tris-tricine gel electrophoresis result for: (1) protein marker, and (2) A $\beta 42$. (C) Binding of Fbg and its fragments was detected by the pAb. (D) Binding of Fbg and its fragments was detected by the $\mathrm{mAb}$.

To further characterize the differential effect of the Fbg and Fbg-GPRP to the binding of the epitope versus the monoclonal and polyclonal antibodies, indirect ELISA was performed. Figure 3 shows that there was not a significant difference in the use of these two antibodies to detect the binding of Fbg and Fbg-GPRP peptide on A $\beta 42$. This interaction study provided additional confirmation of the ELISA study, indicating that either pAb or mAb could have an affinity to the Fbg and Fbg-GPRP. 
(A)

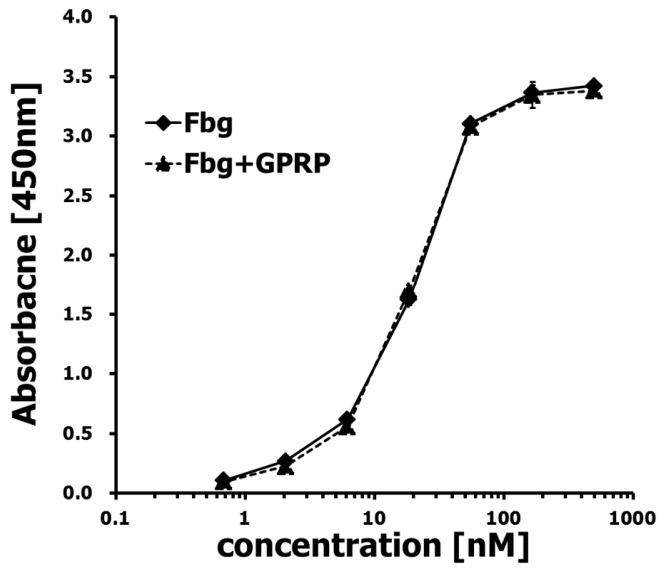

(B)

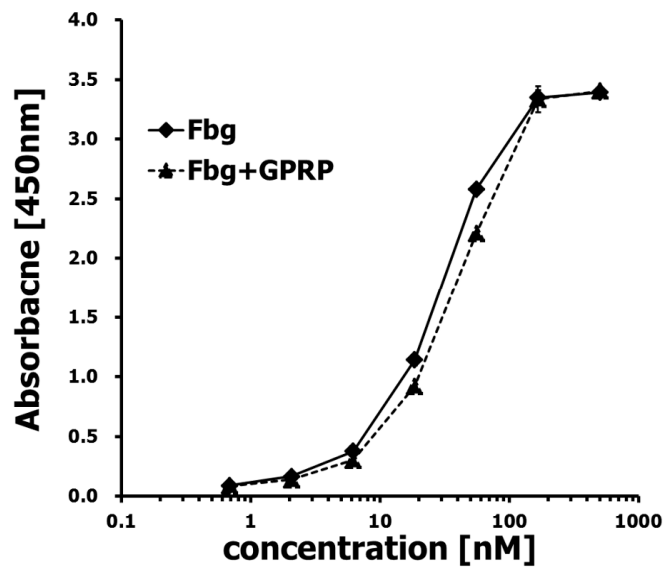

Figure 3. $A \beta 42$ binds to Fbg and Fbg-GPRP peptide (1:50 molar ratio). (A) detecting by polyclonal rabbit anti-Fbg and (B) monoclonal anti-Fbg 85D4.

\subsection{Fbg Binding Analysis Using A 342 Epitope-Mapping ELISA}

To determine which region of $A \beta 42$ is responsible for Fbg binding, fourteen $A \beta$ fragments (numbered 1-14) were analyzed for their ability to bind Fbg and its fragments by monoclonal and polyclonal antibodies assay (Figure $4 \mathrm{~A}$ ). Among the 14 fragments, only A $\beta 5-25$ showed binding to both pAb (Figure $4 \mathrm{~B}$ ) and $\mathrm{mAb}$ (Figure $4 \mathrm{C}$ ) at $\mathrm{N}$-terminus regions.

(A)

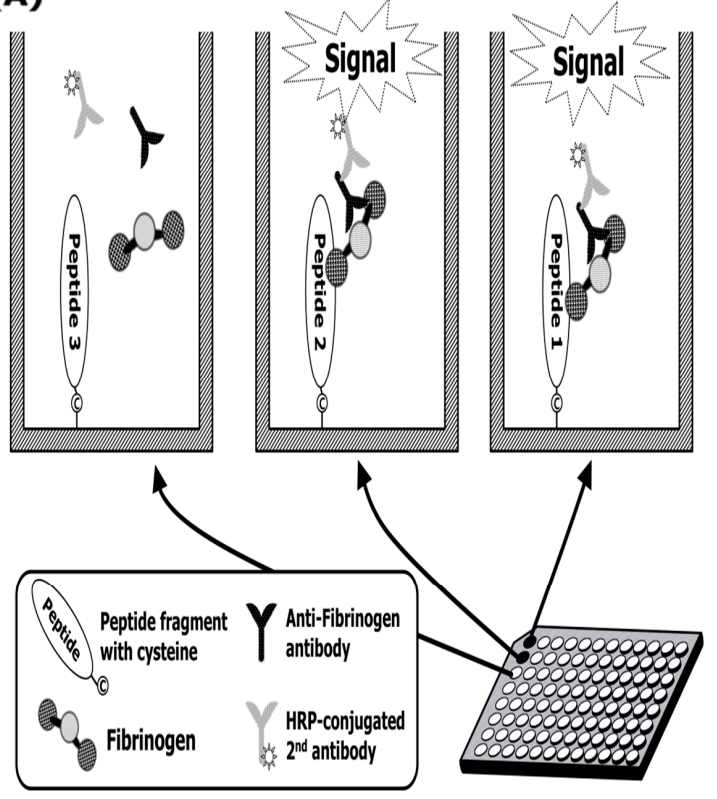

(B)

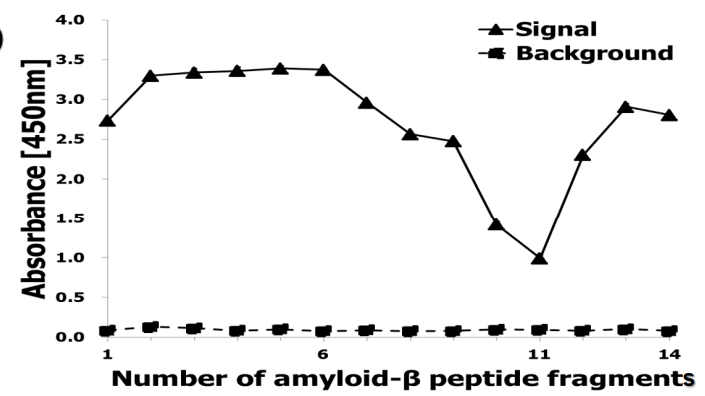

(C)

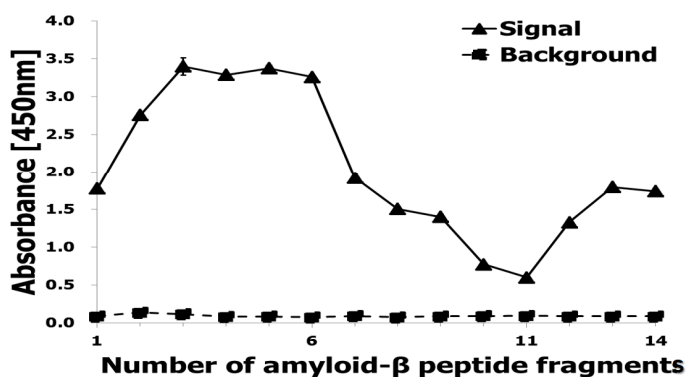

Figure 4. A 342 epitope-mapping ELISA to find a specific site interacting with Fbg. (A) A 342 epitope mapping to detect the site of interaction with Fbg. When Fbg bound to a specific sequence in $A \beta 42$, the corresponding peptide- Fbg complex was detected by anti- Fbg antibody. (B) Fbg attached to the A $\beta 42$ fragments detected by the $\mathrm{pAb}$. (C) Fbg attached to the A $\beta 42$ fragments detected by the $\mathrm{mAb}$. Straight line: $100 \mu \mathrm{L}$ of $20 \mu \mathrm{g} / \mathrm{mL}$ Fbg incubated with the antibody for $2 \mathrm{~h}$ at $25^{\circ} \mathrm{C}$ before the Fbg detection step; dotted line: $100 \mu \mathrm{L}$ of buffer incubated with the antibody for $2 \mathrm{~h}$ at $25^{\circ} \mathrm{C}$ before the Fbg detection step. The straight line indicates non-specific binding of anti-Fbg antibodies.

However, these figures were recorded with a relatively lower affinity to both fragments with numbering 10 and 11. Meanwhile, an unintended interaction between $A \beta_{42}$ fragments and the anti-Fbg antibodies was not observed. Among the fragments \#2 \#6, the consensus sequence 
corresponded to A $\beta 42$ residues 5-25, as presenting Arg-His-Asp-Ser-Gly-Tyr-Glu-Val-His-His-GlnLys-Val-Phe-Ala-Glu-Asp-Val-Gly (Figure 5). In both the monoclonal and polyclonal antibodies, all 19 amino acid residues of the epitope were observed to be essential for the binding, consistent with the high selectivity of the antibodies. In contrast, the A $\beta 42$ sequence $21-33$, which is the consensus sequence for fragments \#10 and \#11, revealed relatively low affinity for Fbg (Figure 4C), which may be due to a loss of affinity of the fragments for those binding sites [14].

\section{Discussion}

$A \beta$ associates with Fbg in vivo and in vitro, which alters the structure of the fibrin clot that is formed [8,10-12]. Since this interaction may have implications for AD pathogenesis, it is critical to gain a better understanding of the biochemical details. In addition, it will be important to which residues of $A \beta$ are involved in this interaction by analyzing the binding of $\mathrm{Fbg}$ to regions of the $A \beta$ peptide. We examined the Fbg-binding region within $A \beta 42$ using an epitope mapping immunoassay analysis. Competitive inhibition of the $A \beta-F b g$ interaction showed that $A \beta 5-25$ (Figure 4) had higher inhibitory efficacy than $A \beta 1-4$ and $A \beta 26-42$, suggesting that the peptide may play a physiological role in modulating A $\beta 42$-mediated effects on fibrin clots. Previously, A $\beta 17-42$ exhibits enhanced aggregation relative to full-length [14], which may be another beneficial consequence of enhancing a-secretase activity as a therapeutic strategy for AD A $\beta 42$ [16]. Additionally, our evidence suggests that the $A \beta-F b g$ interaction might proceed by a new mechanism independent of the known Fbg knob-hole interaction. These previous findings supported a basis for the present study, which was focused on the identification of the essential amino acids within the $A \beta 4-10$ [17] and $A \beta 17-40$ [14] and A $\beta 17-42$ [14] epitope sequences, and on the evaluation of their relative contribution to the interaction with $A \beta$-specific mono- and polyclonal antibodies [18].

One possible explanation for this is that although the $\mathrm{N}$-terminus of $\mathrm{A} \beta 42$ may be directly involved in the interaction between $A \beta 42$ and $\mathrm{Fbg}$, the N-terminal residues of $A \beta 5-25$ increase the stability of $A \beta$ 's tertiary structure and promote its oligomerization, which may promote $A \beta-F b g$ binding to the $A \beta$ fragment with strong affinity to Fbg. Overall, our results suggest that Fbg interacts with the central region of tertiary structured $A \beta 42$, which is stabilized by its N-terminal residues. Our results also suggest that targeting the stable of $A \beta 42$ via its fragment of N-terminal at 5-25 residues may be an alternative strategy for binding $\mathrm{A} \beta 42-\mathrm{Fbg}$ binding.

Furthermore, we also demonstrated that Fbg fragment D contributed predominantly to the interaction, whereas fragment $\mathrm{E}$ showed little contribution. Using an $\mathrm{mAb}$ for Fbg detection, two experiments were conducted, one with and one without $A \beta$. In the absence of $A \beta$, a lower binding profile of the $\mathrm{mAb}$ to Fbg was measured because of the Fbg molecules being in their native conformation, but a higher binding tendency was detected in the presence of $A \beta$ because $A \beta$ binding changed the Fbg conformation, resulting in exposure of a preferred conformational epitope for $\mathrm{mAb}$ binding. Epitope mapping of $A \beta$ demonstrated that Fbg possesses a higher binding affinity to the soluble $\mathrm{N}$-terminus of $\mathrm{A} \beta$. Consistent with this, the $\mathrm{A} \beta$ oligomer, which has the $\mathrm{N}$-termini exposed and the $C$-termini buried in the center of the structure $[19,20]$, seems to have a close relationship to the pathology of $A \beta-F b g$ interaction. Additionally, a fibrin clot formed in the presence of $A \beta$ had unusual fibrinolysis resistance [8]. A $\beta$-Fbg interaction might be the cause of the chronic inflammation seen in AD. Fbg possesses a versatile binding capability [21] and many studies have focused on its interactions. For example, the $\alpha_{\mathrm{IIb}} \beta_{3}$ integrin of platelets [22] and mast cells [23] was able to bind to Fbg.

Moreover, inflammation-related proteins such as toll-like receptor-4 [24], Mac-1 [25], and CD11c/ $\mathrm{CD} 18$ [26] interact with Fbg. Fbg, having multiple binding sites, might also bind with $\mathrm{A} \beta$ fragments as well, forming a signaling pathway by which $A \beta$ could, in principle, potentiate inflammatory processes. The interaction of residues $366-414$ of the Fbg $\beta$ chain with $A \beta$ has been studied, and it is reported that this sequence is located in proximity to the $\beta$ hole in Fbg fragment D [13]. In addition, it was also reported that at high molar ratio, GPRP peptide can bind to the Fbg $\beta$ hole [27]. In the present study, the treatment of Fbg with GPRP peptide had little effect on its ability to bind A $\beta$ (Figure 3), suggesting 
that the $A \beta-F b g$ interaction is independent of knob-hole interaction. One study suggested that the sequence of $\mathrm{Fbg}$ involved in binding to $\mathrm{A} \beta$ inhibits plasmin accessibility, and/or that $A \beta$ attachment to Fbg leads to tight fibrin clot formation [7]. This binding model would be similar to the interaction between $\mathrm{ApoE}$ and $\mathrm{Ab}_{42}$ [28-30], which contributes to its selectivity and high avidity for Ab oligomers and fibrils, including aggregates composed of $\mathrm{N}$-truncated $\mathrm{A} \beta$ variants, without targeting physiologic $\mathrm{Ab}$ monomers. A previous study demonstrated that the binding affinity of soluble $\mathrm{A} \beta$ oligomers to Fbg is nearly 10-fold higher than that of $A \beta$ monomers [31]. These observations are possible clues as to the binding mechanism, but their interpretation is not yet clear. Fbg has previously been proposed as a potential biomarker for diagnosing $\mathrm{AD}$ [32]. Consistent with this, high concentrations of Fbg in the blood may lead to cognitive decline in mild-cognitive-impairment patients [33]. Moreover, a hyperhomocysteinemia showing cognitive decline resembling AD pathology was found to be caused

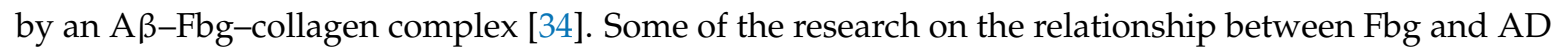
might lead to new therapeutic approaches [5,31,35].

\section{Materials and Methods}

\subsection{Materials}

The whole sequence of the human $A \beta 42$ peptide and its fragments were synthesized for epitope mapping by Lugen Sci Co., Ltd., Seoul, Korea. A dual-color, broad-range, pre-stained marker (7-240 kDa) was also purchased from Lugen. Fbg from human plasma, monoclonal anti-Fbg 85D4 (mAb), phosphate buffered saline (PBS), PBS containing TWEEN $^{\circledR} 20$ (PBST), 3,3 $3^{\prime}, 5,5^{\prime}$ tetramethylbenzidine (TMB) liquid substrate system for ELISA, ethylenediaminetetraacetic acid (EDTA), L-cysteine, Tris base, and 2-mercaptoethanol were purchased from Sigma-Aldrich. Human Fbg fragment E, Pierce Protein-Free (PBF) blocking buffer, Pierce maleimide-activated plates, goat anti-rabbit IgG $(\mathrm{H}+\mathrm{L})$ secondary antibody, HRP conjugate, goat anti-Mouse IgG $(\mathrm{H}+\mathrm{L})$ secondary antibody, HRP conjugate, BupH carbonate-bicarbonate buffer, and Nunc-Immuno ${ }^{\mathrm{TM}}$ MaxiSorp $^{\mathrm{TM}}$ Modules (flat bottom, 96-well format) were obtained from Thermo Scientific. Human Fbg fragment $\mathrm{D}$, polyclonal rabbit anti-Fbg (pAb), and Probumin ${ }^{\circledR}$ bovine serum albumin (BSA) were purchased from Millipore. Electrophoresis equipment and reagents were purchased from Bio-Rad Laboratories (Hercules, CA, USA).

\subsection{The Preparation of the A $\beta 42$ Fragments and A 342 EpiMap ELISA Tests}

Fifteen A $\beta 42$ fragments for epitope mapping were synthesized as per our previous work [36]. Each fragment was composed of 15 amino acids (Figure 5). The fragments formed a series of sequences, each member of the series being shifted along the $A \beta 42$ sequence by an interval of 2 amino acid residues from the previous member. Unfortunately, the peptides numbered 15 failed to be synthesized due to an aggregation problem. These peptides were generated with a cysteine at the end of the N-terminus of the numbered 1-8 and the C-terminus for the peptides 9-14 for linkage to maleimide-activated plates. The interval of 2 amino acids between fragments resulted in a high resolution of the epitope mapping result.

Each high-concentration synthetic A $\beta$ fragment solution in dimethyl sulfoxide (DMSO) was first diluted in a PBS buffer ( $\mathrm{pH}$ 4.5) at a 1:1 volume ratio. These solutions were then further diluted to $25 \mu \mathrm{g} / \mathrm{mL}$ in the PBS buffer (pH 7.2) containing $10 \mathrm{mM}$ EDTA. Each resulting solution was dispensed into Pierce maleimide-activated plates at $100 \mu \mathrm{L}$ per well and incubated overnight at $4{ }^{\circ} \mathrm{C}$ (Figure 6). After 3 PBST washes, unreacted maleimide groups were blocked by adding $200 \mu \mathrm{L}$ of $25 \mu \mathrm{g} / \mathrm{mL}$ L-cysteine solution in PBS and incubating at $25^{\circ} \mathrm{C}$ for $1 \mathrm{~h}$. After 3 PBST washes, $100 \mu \mathrm{L}$ of $20 \mu \mathrm{g} / \mathrm{mL}$ Fbg in PBS $+1 \%$ BSA were aliquotted into the wells and incubated at $25^{\circ} \mathrm{C}$ for $2 \mathrm{~h}$. After 3 PBST washes, $100 \mu \mathrm{L}$ of detection antibody solution (pAb or mAb diluted 1:5000 in PBS $+1 \%$ BSA) were added to the wells and incubated at $25^{\circ} \mathrm{C}$ for $1 \mathrm{~h}$. After 3 PBST washes, HRP-conjugated secondary antibody was diluted 1:5000 in PBS and was added at $100 \mu \mathrm{L}$ per well and incubated at $25^{\circ} \mathrm{C}$ for $1 \mathrm{~h}$. 
After 3 PBST washes, $100 \mu \mathrm{L}$ of TMB substrate was added and incubated at $37^{\circ} \mathrm{C}$ for $25 \mathrm{~min}$. The TMB reaction was stopped by adding $50 \mu \mathrm{L}$ of $2 \mathrm{NH}_{2} \mathrm{SO}_{4}$. Absorbance at $450 \mathrm{~nm}$ was measured with a Victor 3 Perkin-Elmer plate reader. Experimental data were reported as the mean \pm S.E.M. of three replicates.

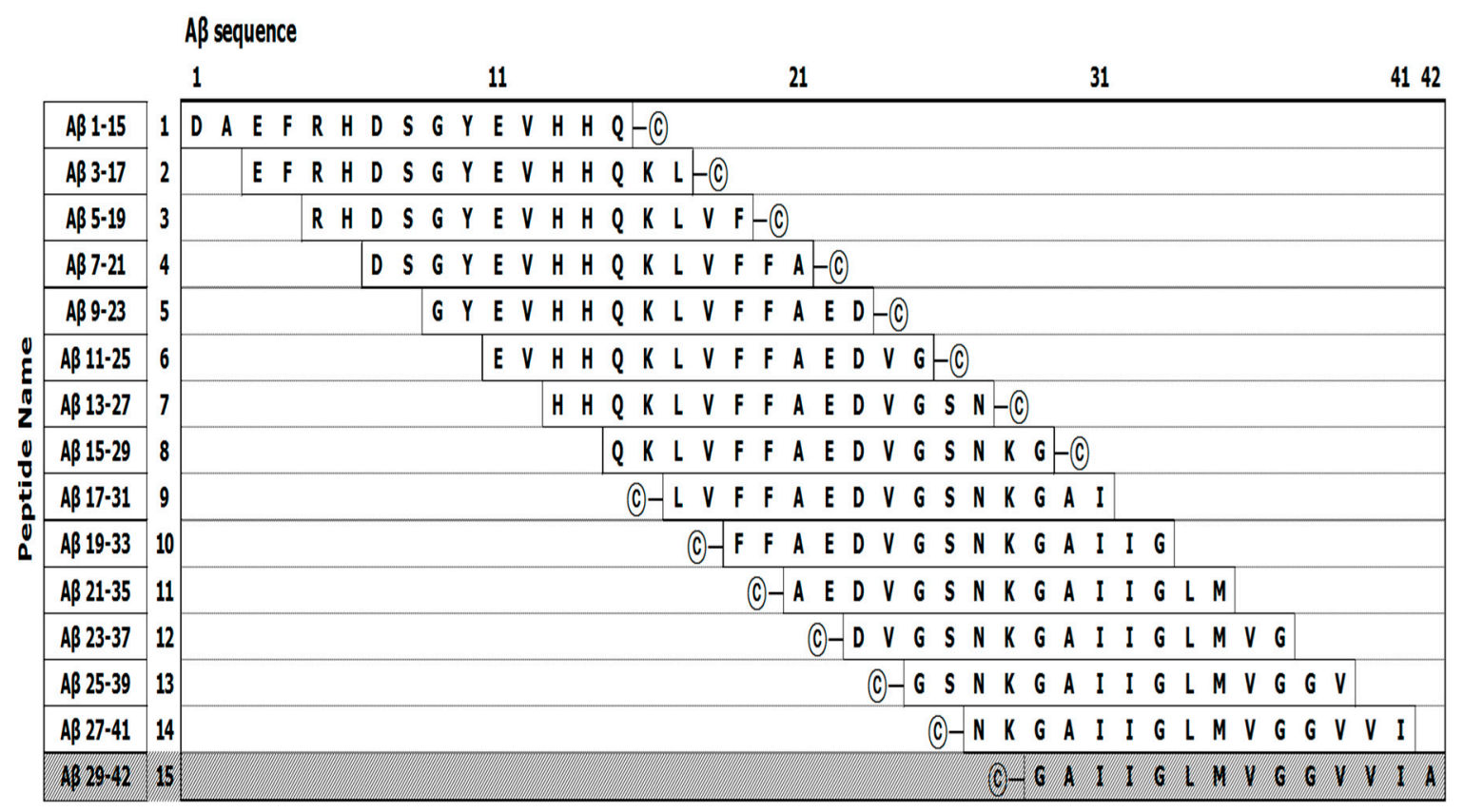

Figure 5. Schematic figures of $A \beta_{1-42}$ (extracellular $\beta$-amyloid 1-42) overlapping peptides. Each fragment was assigned an ID number, and $\subset$ indicates the cysteine residue used for peptide conjugation.
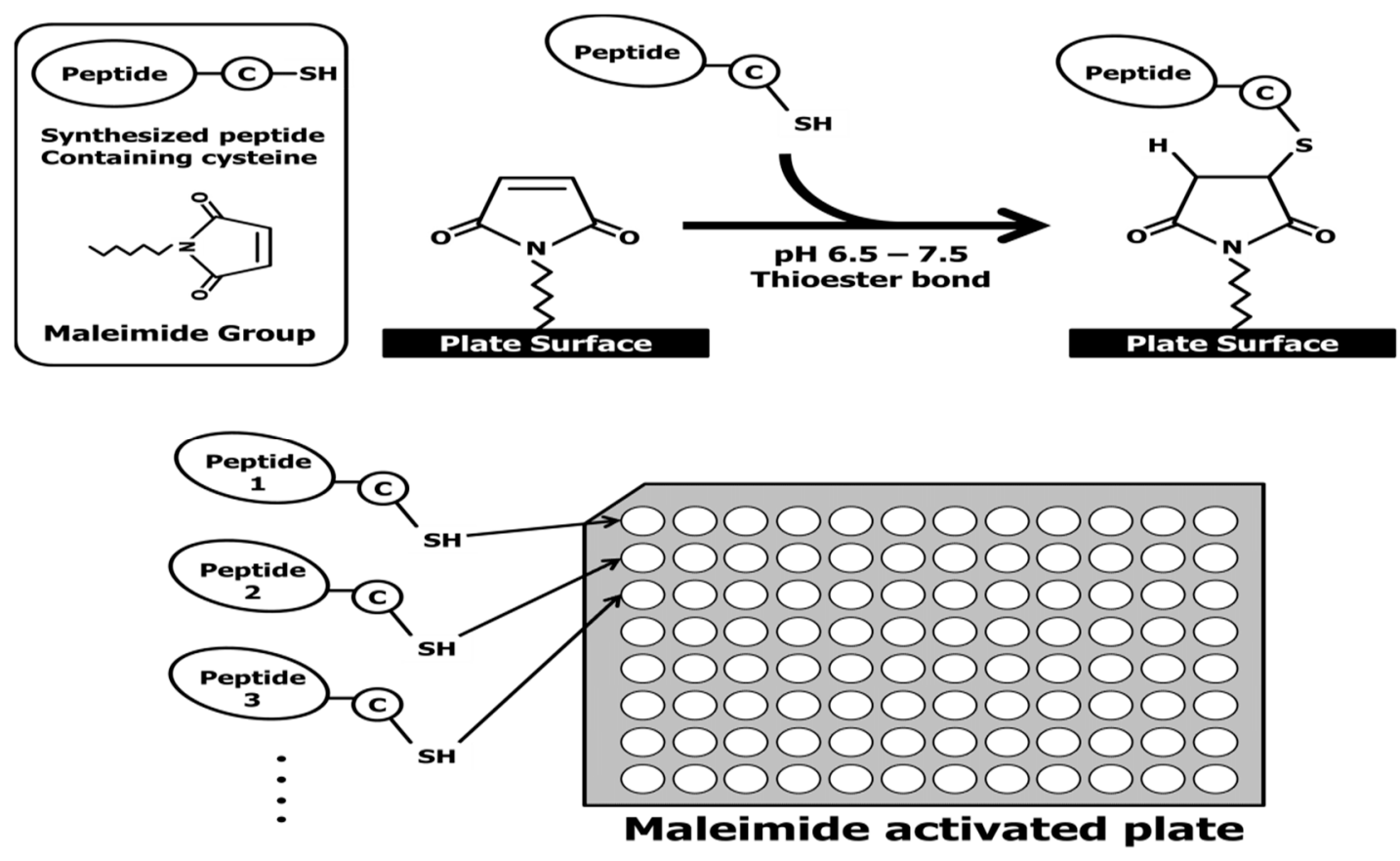

Figure 6. Synthetic A $\beta 42$ fragments were coated on maleimide-activated plates and the principle of epitope-mapping enzyme-linked immunosorbent assay (ELISA) applied.

\subsection{Fbg and Its Fragments Binding Assay Using the Anti-Fbg Antibody}

An indirect ELISA system was used for the anti-Fbg antibody test as described Figure 7. Each of $\mathrm{Fbg}$, Fbg fragment E, and Fbg fragment D was diluted to $2 \mu \mathrm{g} / \mathrm{mL}$ in $100 \mathrm{mM}$ carbonate-bicarbonate buffer, dispensed into a Nunc transparent 96-well plate at $100 \mu \mathrm{L}$ per well, and incubated at $4{ }^{\circ} \mathrm{C}$ 
overnight. After 3 PBST washes, the remaining reactivity of the wells was blocked using Pierce Protein-free blocking buffer at $25^{\circ} \mathrm{C}$ for $1 \mathrm{~h}$. After 3 more PBST washes, the plates were dried in a vacuum chamber for $2 \mathrm{~h}$. Antibodies $\mathrm{pAb}$ from rabbit and $\mathrm{mAb}$ from mouse were serially diluted 1:1000, 1:2000, 1:4000, 1:8000, 1:16,000, 1:32,000, and 1:64,000 in PBS + 1\% BSA, and $100 \mu \mathrm{L}$ of each dilution were aliquotted into the wells. The plates were incubated for $1 \mathrm{~h}$ at $25^{\circ} \mathrm{C}$ and washed 3 times with PBST. Each HRP-conjugated secondary antibody was diluted 1:5000 in PBS starting with a volume of $100 \mu \mathrm{L}$, then $100 \mu \mathrm{L}$ of secondary solution was added to each well and incubated for $1 \mathrm{~h}$ at $25^{\circ} \mathrm{C}$. After 3 PBST washes, $100 \mu \mathrm{L}$ of TMB substrate was added to each well and incubated at $37{ }^{\circ} \mathrm{C}$ for $25 \mathrm{~min}$. The TMB reaction was stopped by adding $50 \mu \mathrm{L}$ of $2 \mathrm{NH}_{2} \mathrm{SO}_{4}$ to each well. Absorbance at $450 \mathrm{~nm}$ was measured with a Victor 3 Perkin-Elmer plate reader. Experimental data were reported as the mean \pm S.E.M. of three replicates.

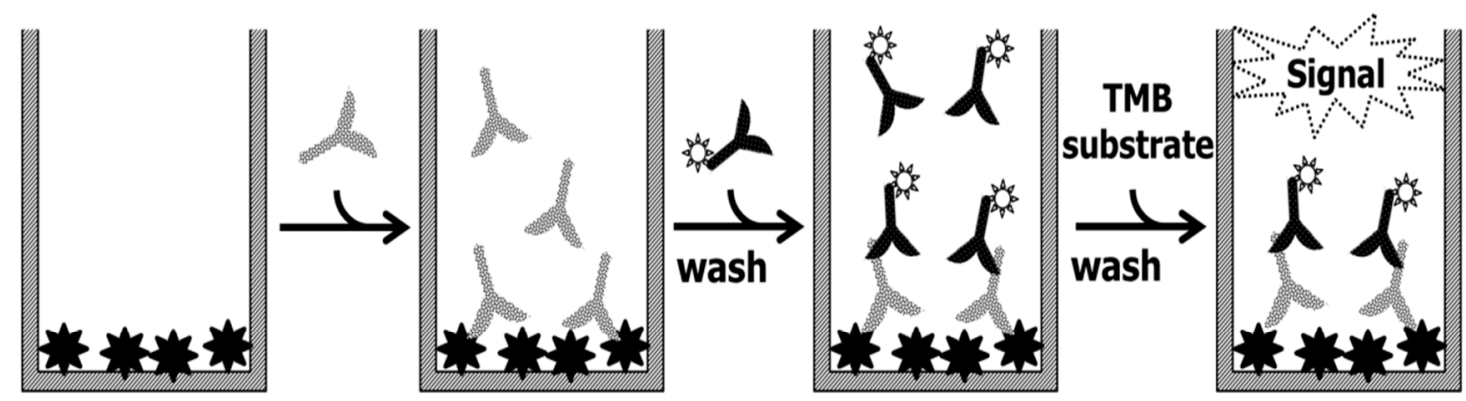

Antigen coating plate

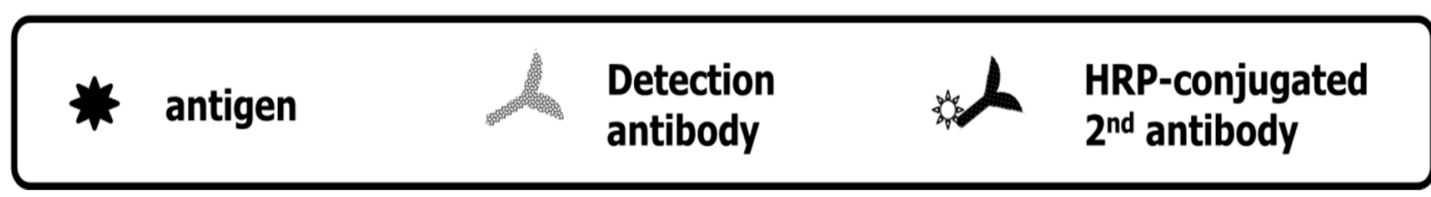

Figure 7. Schematic of indirect ELISA. The antigens were Fbg, Fbg Frag E, and Fbg Frag D. The detection antibodies were $\mathrm{pAb}$ and $\mathrm{mAb}$.

\subsection{ELISA A $342-F b g$ Interaction Assay}

A dilution of $2 \mu \mathrm{g} / \mathrm{mL}$ in $100 \mathrm{mM}$ carbonate-bicarbonate buffer for $10 \mathrm{mg} / \mathrm{mL}$ of $\mathrm{A} \beta$ stock solution in DMSO and $100 \mu \mathrm{L} /$ well were dispensed into a Nunc transparent 96-well plate and incubated at $4^{\circ} \mathrm{C}$ overnight. After 3 PBST washes, the remaining reactivity of the wells was blocked using Pierce protein-free blocking buffer at $25^{\circ} \mathrm{C}$ for $1 \mathrm{~h}$. After 3 PBST washes, the plate was dried in a vacuum chamber for 2 h. Fbg, Fbg fragment E, and Fbg fragment D were each serially diluted 1:1 in PBS + 1\% BSA, starting with $0.5 \mu \mathrm{M}$ and ending with $7.8125 \mathrm{nM}$. These protein solutions were dispensed into $\mathrm{A} \beta$-coated plates at $100 \mu \mathrm{L}$ per well and incubated at $25^{\circ} \mathrm{C}$ for $2 \mathrm{~h}$. After $3 \mathrm{PBST}$ washes, detection antibody solutions (pAb or mAb diluted 1:5000 in PBS $+1 \%$ BSA) were added to the plates at $100 \mu \mathrm{L}$ per well and incubated at $25^{\circ} \mathrm{C}$ for $1 \mathrm{~h}$. After 3 PBST washes, each well received $100 \mu \mathrm{L}$ of HRP-conjugated secondary antibody diluted 1:5000 in PBS followed by incubation at $25^{\circ} \mathrm{C}$ for $1 \mathrm{~h}$. After 3 PBST washes, $100 \mu \mathrm{L}$ of TMB substrate were aliquotted into each well and incubated at $37^{\circ} \mathrm{C}$ for $25 \mathrm{~min}$. The TMB reaction was stopped by adding $50 \mu \mathrm{L}$ of $2 \mathrm{NH}_{2} \mathrm{SO}_{4}$ to the well. Absorbance at $450 \mathrm{~nm}$ was measured with a Victor 3 Perkin-Elmer plate reader as described in Figure 8. Experimental data were reported as the mean \pm S.E.M. of three replicates. 


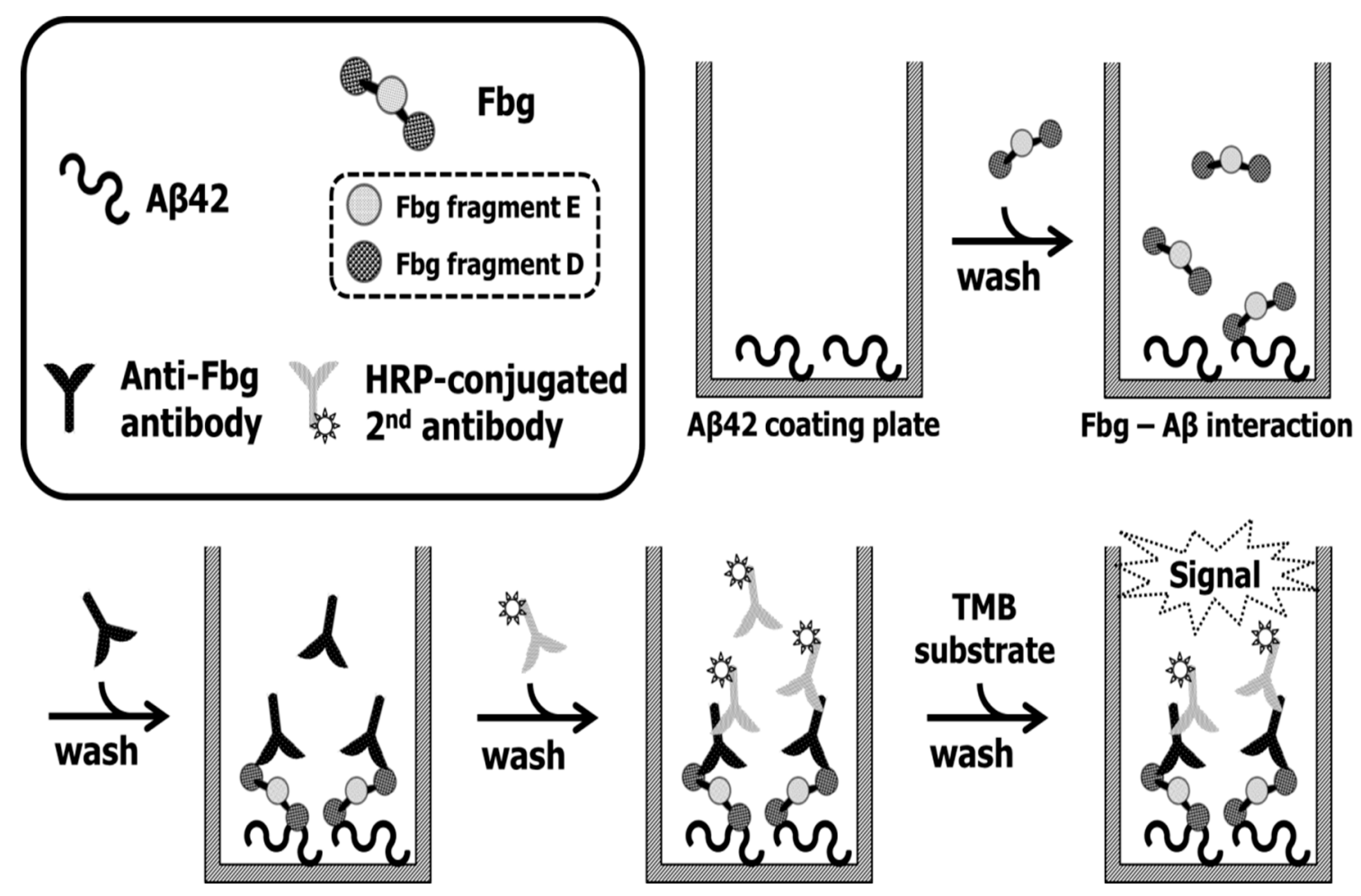

Figure 8. Scheme of the ELISA A $\beta 42-F b g$ (fibrinogen) interaction assay.

To explore Fbg binding under conditions of inhibited Fbg polymerization, a $10 \mathrm{mg} / \mathrm{mL}$ stock solution of Gly-Pro-Arg-Pro (GPRP) peptide in DMSO was mixed with a $1 \mathrm{mg} / \mathrm{mL}$ stock solution of Fbg to produce a 50:1 GPRP:Fbg molar ratio. This solution was serially diluted in PBS $+1 \%$ BSA to $1 / 3$ of the previous concentration at each step, starting with $0.5 \mu \mathrm{M}$ and ending with $685 \mathrm{pM}$. These protein solutions were dispensed into $\mathrm{A} \beta$-coated plates at $100 \mu \mathrm{L}$ per well and incubated at $25^{\circ} \mathrm{C}$ for $2 \mathrm{~h}$. Further processing was the same as above.

\subsection{SDS-Stable Complex Formation}

Laemmli $4 \times$ sample buffers with and without 2-mercaptoethanol were prepared according to the manufacturer's instructions (Sigma-Aldrich, St. Louis, MO, USA). Each 500 ng sample of Fbg, Fbg fragment $\mathrm{E}$, or Fbg fragment $\mathrm{D}$ was mixed with each sample buffer at a 3:1 volume ratio, heated in boiling water for $3 \mathrm{~min}$, and cooled in an ice bath. A 12\% Mini-PROTEAN ${ }^{\circledR}$ TGX $^{\mathrm{TM}}$ gel was used for separation and a $1 \times$ Tris-glycine-SDS running buffer was filled in the gel top and bottom chambers. The samples were loaded, separated slowly, and silver stained.

A $\beta 42$ was prepared as a $500 \mu \mathrm{g} / \mathrm{mL}$ solution in $100 \mathrm{mM}$ carbonate-bicarbonate buffer. After a $4^{\circ} \mathrm{C}$ overnight incubation, a A $\beta 42$ sample was mixed with Tris-tricine sample buffer at a 1:2 volume ratio, heated for $3 \mathrm{~min}$ in boiling water, and cooled in an ice bath. A 10-20\% Mini-PROTEAN ${ }^{\circledR}$ Tris-tricine gel was used for separation. A $1 \times$ Tris-tricine-SDS cathode buffer was filled in the gel top chamber, and a $0.2 \mathrm{M}$ Tris pH 8.9 buffer was filled in the bottom chamber. The $5 \mu \mathrm{g}$ samples were loaded, separated slowly, and silver stained.

\section{Conclusions}

In conclusion, in the present study, we identified the amino acid residues (A $\beta 5-25)$ that are critical to the $A \beta-F b g$ interaction through specific epitope by monoclonal and polyclonal antibodies. The findings of this study also reveal that antibody epitopes within the center of $A \beta$ are potentially important for plaque clearance and neuronal protection via an Fbg-mediated mechanism. These results 
may contribute the development of effective therapeutics against the $A \beta-F b g$ interaction to treat cerebrovascular abnormalities in AD.

Author Contributions: Conceptualization, validation and writing—original draft, V.V.G. and S.S.A.A.; Funding acquisition and supervision, S.S.A.A.

Funding: This research was funded by the National Research Foundation of Korea (NRF) grant by Korean Government NRF-2017R1A2B4012636 and Gachon University Research Grant (2018-0682).

Acknowledgments: The authors gratefully acknowledge the experimental results of MSc. SeunOh Bae from the Department of Bionano Technology.

Conflicts of Interest: The authors declare no conflict of interest.

\section{References}

1. Attems, J.; Jellinger, K.A. The overlap between vascular disease and Alzheimer's disease-lessons from pathology. BMC Med. 2014, 12, 206. [CrossRef] [PubMed]

2. Giau, V.V.; Bagyinszky, E.; An, S.S.A.; Kim, S. Clinical genetic strategies for early onset neurodegenerative diseases. Mol. Cell. Toxicol. 2018, 14, 123-142. [CrossRef]

3. Giau, V.V.; Wu, S.Y.; Jamerlan, A.; An, S.S.A.; Kim, S.Y.; Hulme, J. Gut Microbiota and Their Neuroinflammatory Implications in Alzheimer's Disease. Nutrients 2018, 10, 1765. [CrossRef] [PubMed]

4. Wang, M.J.; Yi, S.; Han, J.Y.; Park, S.Y.; Jang, J.W.; Chun, I.K.; Giau, V.V.; Bagyinszky, E.; Lim, K.T.; Kang, S.M.; et al. Analysis of Cerebrospinal Fluid and [11C]PIB PET Biomarkers for Alzheimer's Disease with Updated Protocols. J. Alzheimer's Dis. 2016, 52, 1403-1413. [CrossRef] [PubMed]

5. Van Giau, V.; An, S.S.A.; Hulme, J.P. Mitochondrial therapeutic interventions in Alzheimer's disease. J. Neurol. Sci. 2018, 395, 62-70. [CrossRef] [PubMed]

6. Weisel, J.W. Fibrinogen and fibrin. Adv. Protein Chem. 2005, 70, 247-299. [PubMed]

7. Zamolodchikov, D.; Strickland, S. Abeta delays fibrin clot lysis by altering fibrin structure and attenuating plasminogen binding to fibrin. Blood 2012, 119, 3342-3351. [CrossRef] [PubMed]

8. Cortes-Canteli, M.; Paul, J.; Norris, E.H.; Bronstein, R.; Ahn, H.J.; Zamolodchikov, D.; Bhuvanendran, S.; Fenz, K.M.; Strickland, S. Fibrinogen and beta-amyloid association alters thrombosis and fibrinolysis: A possible contributing factor to Alzheimer's disease. Neuron 2010, 66, 695-709. [CrossRef] [PubMed]

9. Bagyinszky, E.; Giau, V.V.; Shim, K.; Suk, K.; An, S.S.A.; Kim, S. Role of inflammatory molecules in the Alzheimer's disease progression and diagnosis. J. Neurol. Sci. 2017, 376, 242-254. [CrossRef]

10. Cortes-Canteli, M.; Mattei, L.; Richards, A.T.; Norris, E.H.; Strickland, S. Fibrin deposited in the Alzheimer's disease brain promotes neuronal degeneration. Neurobiol. Aging 2015, 36, 608-617. [CrossRef]

11. Hultman, K.; Cortes-Canteli, M.; Bounoutas, A.; Richards, A.T.; Strickland, S.; Norris, E.H. Plasmin deficiency leads to fibrin accumulation and a compromised inflammatory response in the mouse brain. J. Thromb. Haemost. 2014, 12, 701-712. [CrossRef] [PubMed]

12. Klohs, J.; Baltes, C.; Princz-Kranz, F.; Ratering, D.; Nitsch, R.M.; Knuesel, I.; Rudin, M. Contrast-enhanced magnetic resonance microangiography reveals remodeling of the cerebral microvasculature in transgenic ArcAbeta mice. J. Neurosci. 2012, 32, 1705-1713. [CrossRef] [PubMed]

13. Ahn, H.J.; Zamolodchikov, D.; Cortes-Canteli, M.; Norris, E.H.; Glickman, J.F.; Strickland, S. Alzheimer's disease peptide beta-amyloid interacts with fibrinogen and induces its oligomerization. Proc. Natl. Acad. Sci. USA 2010, 107, 21812-21817. [CrossRef] [PubMed]

14. Zamolodchikov, D.; Berk-Rauch, H.E.; Oren, D.A.; Stor, D.S.; Singh, P.K.; Kawasaki, M.; Aso, K.; Strickland, S.; Ahn, H.J. Biochemical and structural analysis of the interaction between beta-amyloid and fibrinogen. Blood 2016, 128, 1144-1151. [CrossRef]

15. Felding-Habermann, B.; Ruggeri, Z.M.; Cheresh, D.A. Distinct biological consequences of integrin alpha v beta 3-mediated melanoma cell adhesion to fibrinogen and its plasmic fragments. J. Biol. Chem. 1992, 267, 5070-5077. [PubMed]

16. Lichtenthaler, S.F. alpha-secretase in Alzheimer's disease: Molecular identity, regulation and therapeutic potential. J. Neurochem. 2011, 116, 10-21. [CrossRef] 
17. Manea, M.; Przybylski, M.; Hudecz, F.; Mezo, G. Design, structural, and immuno-analytical properties of antigenic bioconjugates comprising a beta-amyloid-plaque specific epitope. Biopolymers 2008, 90, 94-104. [CrossRef]

18. Stefanescu, R.; Lupu, L.; Manea, M.; Iacob, R.E.; Przybylski, M. Molecular characterization of the beta-amyloid(4-10) epitope of plaque specific Abeta antibodies by affinity-mass spectrometry using alanine site mutation. J. Peptide Sci. 2018, 24, e3047. [CrossRef]

19. Barghorn, S.; Nimmrich, V.; Striebinger, A.; Krantz, C.; Keller, P.; Janson, B.; Bahr, M.; Schmidt, M.; Bitner, R.S.; Harlan, J.; et al. Globular amyloid beta-peptide oligomer-A homogenous and stable neuropathological protein in Alzheimer's disease. J. Neurochem. 2005, 95, 834-847. [CrossRef]

20. Ahmed, M.; Davis, J.; Aucoin, D.; Sato, T.; Ahuja, S.; Aimoto, S.; Elliott, J.I.; Van Nostrand, W.E.; Smith, S.O. Structural conversion of neurotoxic amyloid-beta(1-42) oligomers to fibrils. Nat. Struct. Mol. Biol. 2010, 17, 561-567. [CrossRef]

21. Davalos, D.; Akassoglou, K. Fibrinogen as a key regulator of inflammation in disease. Semin. Immunopathol. 2012, 34, 43-62. [CrossRef] [PubMed]

22. Holmbäck, K.; Danton, M.J.; Suh, T.T.; Daugherty, C.C.; Degen, J.L. Impaired platelet aggregation and sustained bleeding in mice lacking the fibrinogen motif bound by integrin alpha Ilb beta 3. EMBO J. 1996, 15, 5760-5771. [CrossRef] [PubMed]

23. Oki, T.; Kitaura, J.; Eto, K.; Lu, Y.; Maeda-Yamamoto, M.; Inagaki, N.; Nagai, H.; Yamanishi, Y.; Nakajima, H.; Kumagai, H.; et al. Integrin alphaIlbbeta3 induces the adhesion and activation of mast cells through interaction with fibrinogen. J. Immunol. 2006, 176, 52-60. [CrossRef] [PubMed]

24. Smiley, S.T.; King, J.A.; Hancock, W.W. Fibrinogen stimulates macrophage chemokine secretion through toll-like receptor 4. J. Immunol. 2001, 167, 2887-2894. [CrossRef] [PubMed]

25. Lishko, V.K.; Podolnikova, N.P.; Yakubenko, V.P.; Yakovlev, S.; Medved, L.; Yadav, S.P.; Ugarova, T.P. Multiple binding sites in fibrinogen for integrin alphaMbeta2 (Mac-1). J. Biol. Chem. 2004, 279, 44897-44906. [CrossRef] [PubMed]

26. Nham, S.U. Characteristics of fibrinogen binding to the domain of CD11c, an alpha subunit of p150,95. Biochem. Biophys. Res. Commun. 1999, 264, 630-634. [CrossRef] [PubMed]

27. Laudano, A.P.; Doolittle, R.F. Studies on synthetic peptides that bind to fibrinogen and prevent fibrin polymerization. Structural requirements, number of binding sites, and species differences. Biochemistry 1980, 19, 1013-1019. [CrossRef]

28. Munson, G.W.; Roher, A.E.; Kuo, Y.M.; Gilligan, S.M.; Reardon, C.A.; Getz, G.S.; LaDu, M.J. SDS-stable complex formation between native apolipoprotein E3 and beta-amyloid peptides. Biochemistry 2000, 39, 16119-16124. [CrossRef]

29. Giau, V.V.; Bagyinszky, E.; An, S.S.; Kim, S.Y. Role of apolipoprotein E in neurodegenerative diseases. Neuropsychiatr. Dis. Treat. 2015, 11, 1723-1737. [CrossRef]

30. Youn, Y.C.; Lim, Y.K.; Han, S.H.; Giau, V.V.; Lee, M.K.; Park, K.Y.; Kim, S.; Bagyinszky, E.; An, S.S.A.; Kim, H.R. Apolipoprotein epsilon7 allele in memory complaints: Insights through protein structure prediction. Clin. Interv. Aging 2017, 12, 1095-1102. [CrossRef]

31. Ahn, H.J.; Glickman, J.F.; Poon, K.L.; Zamolodchikov, D.; Jno-Charles, O.C.; Norris, E.H.; Strickland, S. A novel Abeta-fibrinogen interaction inhibitor rescues altered thrombosis and cognitive decline in Alzheimer's disease mice. J. Exp. Med. 2014, 211, 1049-1062. [CrossRef] [PubMed]

32. Lee, J.W.; Namkoong, H.; Kim, H.K.; Kim, S.; Hwang, D.W.; Na, H.R.; Ha, S.-A.; Kim, J.-R.; Kim, J.W. Fibrinogen gamma-A chain precursor in CSF: A candidate biomarker for Alzheimer's disease. BMC Neurol. 2007, 7, 14. [CrossRef] [PubMed]

33. Xu, G.; Zhang, H.; Zhang, S.; Fan, X.; Liu, X. Plasma fibrinogen is associated with cognitive decline and risk for dementia in patients with mild cognitive impairment. Int. J. Clin. Pract. 2008, 62, 1070-1075. [CrossRef] [PubMed]

34. Muradashvili, N.; Tyagi, R.; Metreveli, N.; Tyagi, S.C.; Lominadze, D. Ablation of MMP9 gene ameliorates paracellular permeability and fibrinogen-amyloid beta complex formation during hyperhomocysteinemia. J. Cereb. Blood Flow Metab. 2014, 34, 1472-1482. [CrossRef] [PubMed] 
35. Nguyen, T.T.; Giau, V.V.; Vo, T.K. Current advances in transdermal delivery of drugs for Alzheimer's disease. Indian J. Pharmacol. 2017, 49, 145-154. [PubMed]

36. Kang, M.; Kim, S.Y.; An, S.S.; Ju, Y.R. Characterizing affinity epitopes between prion protein and beta-amyloid using an epitope mapping immunoassay. Exp. Mol. Med. 2013, 45, e34. [CrossRef] [PubMed] 